\title{
Essential Tremor: From Bedside to Bench and Back to Bedside
}

\author{
Elan D. Louis, MD, MSc ${ }^{1,2,3,4}$ \\ ${ }^{1}$ GH Sergievsky Center, College of Physicians and Surgeons, Columbia University, New York, \\ NY, USA \\ ${ }^{2}$ Department of Neurology, College of Physicians and Surgeons, Columbia University, New York, \\ NY, USA \\ ${ }^{3}$ Department of Epidemiology, Mailman School of Public Health, Columbia University, New York, \\ NY, USA \\ ${ }^{4}$ Taub Institute for Research on Alzheimer's Disease and the Aging Brain, College of Physicians \\ and Surgeons, Columbia University, New York, NY, USA
}

\begin{abstract}
Purpose-The last several years have witnessed a remarkable increase in research on essential tremor (ET), with consequent advances in our understanding of this entity. An attempt to both summarize and frame this work has not been undertaken.
\end{abstract}

Recent Findings-Here, I show that observations on ET arising from clinical practice/clinical studies have guided scientific studies of this disorder. In turn, the results of scientific studies are beginning to be translated back to the bedside to improve treatment. Recent ET research has given rise to several novel and intriguing ideas about the disease. These include the following: 1. ET may represent a family of diseases rather than a single disease. 2. ET seems to be a disease of the cerebellum or cerebellar system. 3. ET may be neurodegenerative. 4. Low gamma aminobutyric acid tone seems to be a central feature of ET. As with many emerging ideas, there is significant discussion and debate over these emerging ideas, and this fuels additional scientific studies.

Summary-The flow of ideas, from clinical observations about ET, to their translation into scientific studies, and their translation back to the bedside is expected to eventually lead to improvements at the patient interface.

\section{Keywords}

essential tremor; cerebellum; neurodegenerative; gamma aminobutyric acid; clinical; biology; pathophysiology

Correspondence: Elan Louis, Unit 198, Neurological Institute, 710 West 168th Street, New York, NY, 10032, USA. Tel: (212) 305-9194, Fax: (212) 305-1304, EDL2@ columbia.edu.

Conflict of Interest: There are no conflicts of interest or competing financial interests. 


\section{Introduction}

Essential tremor (ET) is among the primary (i.e., most common) movement disorders, and the most prevalent tremor disorder. ${ }^{1}$ Therefore, its importance as a clinical entity should not be underestimated. The last several years have witnessed a remarkable increase in ET research, with consequent advances in our understanding of ET. Observations arising from clinical practice and clinical studies have been translated to the bench to inform and guide scientific studies of this disorder. In turn, the results of scientific studies are beginning to be translated back to the bedside to improve treatment. Hence, we are beginning to see a flow of ideas and concepts back and forth across clinical and scientific realms. As with many fresh and emerging ideas, there is significant discussion and debate. The main ideas are the following:

1. ET may represent a family of diseases rather than a single disease.

2. ET seems to be a disease of the cerebellum or cerebellar system.

3. ET may be neurodegenerative.

4. Low gamma aminobutyric acid (GABA) tone seems to be a central feature of ET.

The goal of this paper is to present the recent advances in the ET field within the above conceptual framework. Additionally, I wish to emphasize the translational nature of these ideas. Hence, I will review their origins in clinical observations (i.e., at the bedside), their support in scientific studies (i.e., at the bench), and the implications for an improved patient interface (i.e., back at the bedside).

\section{ET may represent a family of diseases rather than a single disease}

ET may comprise a family of diseases rather than a single entity. Below, this concept is elaborated upon.

\section{Bedside}

Although for many years ET was viewed as a monosymptomatic condition, ${ }^{2}$ we now know that the clinical features are richer, including both motor and non-motor features. ${ }^{3}$ To begin with, the tremor itself is not a featureless, nondescript action tremor; rather, it is characterized by a specific pattern of features: (1) kinetic tremor is greater in amplitude than postural tremor; ${ }^{4,5}(2)$ the tremor involves movement at specific joints in specific directions (e.g. wrist tremor is greater than metacarpal tremor, wrist flexion-extension tremor is greater than wrist rotation tremor); ${ }^{6,7}$ (3) intention tremor of the arms is seen on finger-nose-finger maneuver in approximately $50 \%$ of cases ${ }^{8,9}$ (4) rest tremor occurs in as many as $20 \%$ of cases as a late feature; ${ }^{10}(5)$ arm tremor precedes cranial tremor, for which there is a female preponderance; ${ }^{11,12}(6)$ the prevalence of neck tremor is greater than that of jaw tremor, which is greater than that of tongue/cheek/forehead tremor; ${ }^{13}, 14$ and (7) there is a tendency for tremor severity to increase over time. ${ }^{15-17}$ These features distinguish the tremor of ET from that of Parkinson's disease, dystonia, and drug-induced tremor. Aside from tremor, other motor features have been described in ET, including abnormalities in tandem gait and balance (i.e., the presence of a mild gait ataxia). ${ }^{11,18-25}$ In some patients, the gait problem is 
marked, putting them at increased falls risk. ${ }^{26}$ Furthermore, oculomotor deficits indicative of cerebellar dysfunction ${ }^{27,28}$ have been reported, as well as impairments in both temporal variability of voluntary movement and predictions in timing of movement, each under cerebellar control. ${ }^{29-31}$ The clinical features of ET also include non-motor features, ${ }^{3}$ including cognitive problems ranging from mild to severe ${ }^{32}$ and psychiatric problems, ${ }^{33,}, 34$ some of which could be primary. ${ }^{34}$ Thus, over the past $5-10$ years, there has been a growing appreciation that the clinical phenomenology is varied in nature, and furthermore, this variance may be differentially expressed across patients. ${ }^{17,} 35,36$ While some of the differences across patients can clearly be attributed to differences in disease duration (i.e., disease stage), others cannot (i.e., patients with similar disease stages may have different features). ${ }^{37}$ This gives rise to the idea of different disease subtypes or even different disease entities. ${ }^{17,38}$ Based on available evidence, it is somewhat premature to propose specific clinical subtypes of ET; however, a number of clinical features, including age of onset, family history, presence of head tremor, and presence/severity of cerebellar signs, are likely to be among the key features on which classification schemes are eventually constructed.

\section{Bench}

Laboratory-based studies lend further support for the notion that ET is heterogeneous. These studies include neuroimaging, postmortem, and genetic studies, each discussed below.

Although a recent single photon emission computed tomography (SPECT) study of 13 ET patients with limb tremor and 11 with only head tremor, found no difference between the two groups in terms of perfusion changes in the cerebellum and other brain structures, ${ }^{39} \mathrm{a}$ growing number of imaging studies do suggest such differences. Thus, a voxel based morphometry study of 50 ET patients reported differences in the cerebellar vermis between patients with arm tremor vs. patients with both arm and head tremor, leading the authors to conclude that these could represent distinct subtypes of the disease. ${ }^{40}$ A study of 20 ET patients that used voxel-based morphometry similarly detected differences between ET patients with vs. without head tremor, leading the authors to suggest that patients with additional head tremor may represent a distinct subgroup of ET. ${ }^{41}$ In another study, which used an automated volumetric method to quantify subcortical atrophy, the investigators noted differences between ET patients with vs. without head tremor in terms of cerebellar volume loss, again suggesting the presence of two subtypes of ET. ${ }^{42}$

Postmortem studies all agree that there is heterogeneity in ET brains, ${ }^{43-45}$ and this lead early investigators to conclude that there was "no consistent pattern of pathology". ${ }^{44}$ However, recent controlled studies, using larger samples, have attempted to order this heterogeneity. At the Essential Tremor Centralized Brain Repository, while the vast bulk of ET cases have structural/degenerative changes in the cerebellum ("cerebellar ET"), smaller subgroups of patients have other findings, which have been broadly categorized as Lewy-body containing brains, ${ }^{45,46}$ and other brains have ubiquitinated intranuclear inclusions. ${ }^{47}$ Another subgroup of ET cases seems more prone to develop superimposed progressive supranuclear palsy. ${ }^{48}$ Organizing this heterogeneity is a challenge and additional studies are needed to fully understand and encapsulate it. 
Genetic studies similarly support the presence of different genetic mechanisms for ET and the presence of clear genetic heterogeneity. ${ }^{49-51}$ It is expected that the search for ET genes will lead to many different genetic forms of this disease (i.e., many ETs).

In summary, laboratory-based studies (neuroimaging, postmortem, and genetic) provide support for the notion that ET is a heterogeneous condition, thereby resonating with clinical studies that suggest that ET is perhaps multiple diseases.

\section{Bedside}

How do these basic findings from the laboratory translate back into the clinical arena? It would be important to tailor clinical trials, and eventually clinical practice, to account for the clinical and biological heterogeneity of ET. ${ }^{52}$ Among clinicians and clinical trialists, the traditional approach has largely been to regard ET patients as a single, homogeneous group. ${ }^{52}$ Perhaps the only exception is the occasional separation of patients with head tremor from patients with upper limb tremor. ${ }^{53,54}$ This "one size fits all" approach is potentially problematic because it increases the occurrence of Type II errors in clinical trials (i.e., failing to reject the null hypothesis when there is a treatment effect) ${ }^{52}$ and therapeutic failure in clinical settings.

That investigators are beginning to think along these lines is evidenced by a recent study of a group of $32 \mathrm{ET}$ patients who differed with respect to propranolol responsiveness. The authors reported that the non-responder group showed more severe atrophy in the left orbitofrontal cortex and right temporal cortex relative to responders. However, the responders exhibited significantly lower fractional anisotropy values in the bilateral frontal, corpus callosal, and right parietotemporal white matter compared with the non-responder group. They concluded that propranolol responsiveness may be a predictive factor to determine ET subtypes in terms of neuroanatomical heterogeneity. ${ }^{55}$

\section{ET seems to be a disease of the cerebellum or cerebellar system}

Accumulating evidence suggests that ET is a disease of the cerebellar and/or cerebellar system.

\section{Bedside}

As noted above, an emerging clinical literature has gathered increasing support for the notion that the cerebellum is centrally involved in ET. First, cerebellar-like problems, with abnormalities in tandem gait and balance, have been repeatedly described in ET patients. ${ }^{11,20,21,25,56-59}$ Intention (i.e., "cerebellar") tremor of the arms occurs in approximately one-half of ET patients, ${ }^{8,60}$ and in $10 \%$ of patients, intention tremor involves the head as well. ${ }^{59,61}$ There are a variety of other motor abnormalities that point to what is likely to be a more pervasive underlying abnormality of cerebellar function in ET. These include oculomotor deficits 27,28 and abnormalities in limb motor behavior in ET. ${ }^{29-31,59,62}$ Second, unilateral cerebellar stroke has been reported to abruptly terminate ipsilateral arm tremor in patients with $\mathrm{ET}^{63,64}$ and cerebellar outflow (dentato-rubro-thalamic) pathways are the target of deep brain stimulation, which is highly effective in treating ET. ${ }^{59,65,66}$ The presence of a myriad of cerebellar features strongly implicates the cerebellar system. 


\section{Bench}

Current neuroimaging research provides converging evidence for the central role of the cerebellum in the pathophysiology of ET ${ }^{67}$ Thus, a growing array of neuroimaging studies indicate the presence of functional and metabolic abnormalities in the ET cerebellum, as well as structural abnormalities in both the cerebellar gray and white matter. These include functional magnetic resonance imaging (MRI) studies, ${ }^{68}$ positron emission tomography (PET) studies, ${ }^{69-71}\left[{ }^{1} \mathrm{H}\right]$ magnetic resonance spectroscopic imaging studies, ${ }^{72,73}$ diffusion tensor imaging studies, ${ }^{74-76}$ voxel based morphometry studies,${ }^{40,77}$ and studies using other automated volumetric methods. ${ }^{78}$

Postmortem studies of ET, from different groups, consistently report abnormalities in the neocerebellum. These abnormalities include an increase in number of Purkinje cell dendritic swellings $;{ }^{79}$ reductions in Purkinje cell counts in some studies and in Purkinje cell linear density in others; heterotopic placement of Purkinje cell soma; ${ }^{45,80,81}$ a broad range of changes in Purkinje cell axonal morphology, including torpedoes; ${ }^{3}, 45$ increased Bergmann gliosis; 43 abnormalities in basket cell axonal processes (i.e., hypertrophy of perisomal processes ["hairy baskets"]; elongated LINGO1 labeled pinceau processes); ${ }^{82,83}$ and reductions in GABA(A) and GABA(B) receptors in the dentate nucleus. ${ }^{84}$ Systematic postmortem study of the other brain regions that form loop connections with the cerebellum (i.e., the thalamus, inferior olivary nucleus, red nucleus, and motor cortex) indicate that significant pathologic changes are not evident in these brain regions, ${ }^{43}, 44$ reinforcing the notion that the cerebellum is the focal point of interest in studies of the pathogenesis of ET.

Bedside-The surgical treatments for ET are among the most effective, particularly if one considers the sheer magnitude and immediacy of the reduction in tremor amplitude. ${ }^{65,85,86}$ Of interest is that there is less response heterogeneity with deep brain stimulation surgery, with the large majority of ET patients showing a sizable response to the intervention, ${ }^{65}$ than there is for pharmacological treatments. For a variety of pharmacological clinical trials in ET, treatment graphs (before and after treatment) clearly show that a sizable portion (30 $60 \%$ ) of patients has little response to medication. ${ }^{17}$

The number of surgical modalities/options is growing ${ }^{87}$ It should be pause for thought that all of these surgeries, in all of their variety, intervene at the same place, namely, the cerebellar outflow region (thalamus). This is a final common nodal point for the receipt of diatheses-affected pathways that emerge from more proximal points within the cerebellar system in ET. ${ }^{17}$ This is a clear indicator that future treatments for ET, whether they be surgical or pharmacotherapeutic, need to take cerebellar pathophysiology and cerebellar outflow pathways into account. They need to consider on a far more fundamental level how the cerebellum works, what the specific problem or problems are occurring in this particular brain region in ET, and how to effectively intervene.

\section{ET may be neurodegenerative}

The notion that ET may be neurodegenerative is one that has been proposed recently. 


\section{Bedside}

ET shares a number of important features with the neurodegenerative diseases. Thus, clinical experience and clinical research indicate that ET has an insidious onset ${ }^{88,89}$ and it then follows a gradual yet progressive clinical course. ${ }^{15}, 16$ Several patterns of progression have been described. ${ }^{90}$ There is a spread of tremor somatopically across body regions (arms to cranial structures) with time, as well as the development of more extensive tremor manifestations (rest tremor and intention tremor) with disease progression. ${ }^{9}{ }^{10}$ Furthermore, both the incidence and the prevalence of ET increase with age and aging, with an exponential increase in prevalence in advanced age. ${ }^{1,91,92}$ Additionally, carefullycontrolled prospective studies indicate that prevalent ET is associated with an increased risk of several degenerative disorders, including Parkinson's disease and Alzheimer's disease. ${ }^{93-95}$

\section{Bench}

Postmortem studies of ET indicate that the vast bulk of ET cases have changes in the cerebellum ("cerebellar ET") that are likely to be of a degenerative nature, while smaller subgroups of patients have other degenerative findings, which may be broadly categorized as Lewy-body containing brains, ${ }^{45,} 46$ and brains with ubiquitinated intranuclear inclusions. ${ }^{47}$ There is some debate over the issue of Purkinje cell loss in ET, ${ }^{96}$ however, the changes that occur in the ET brain, aside from any Purkinje cell loss, are numerous, ${ }^{97}$ and are the types of changes that are seen in cerebellar degenerations (e.g., spinocerebellar ataxias).

\section{Bedside}

The conceptualization of ET as a neurodegenerative process ${ }^{98}$ has several clinical implications. It indicates that there is a cellular and molecular pathophysiology of ET and the disease is not merely the result of an electrical disarrangement. This means that the future drug development could target important molecular and cellular events in the degenerative cascade. This being said, other than levodopa therapy for Parkinson's disease, the treatment options for neurodegenerative diseases are quite limited. Another clinical implication is that, moving forward, this makes the identification of modifiable risk factors more important, along with strategies aimed at disease prevention. In addition, it raises as a central issue that of the rational development of neuroprotective agents.

\section{Low GABA tone seems to be a central feature of ET}

A central feature of ET may be a reduction in GABA tone. Below, this concept is elaborated upon.

\section{Bedside}

An interesting feature of the treatment of ET is that nearly all effective medications involve the enhancement of a single and specific brain neurotransmitter system - the GABA-ergic system. These medications include the barbiturates, primidone, benzodiazepines, gabapentin, topiramate, and even various alcohols. ${ }^{99,} 100$ This indicates that there is a specific central target of underlying biological importance. ${ }^{17,}{ }^{100}$ Propranolol is believed to 
have a therapeutic effect in ET by antagonistic binding to nonspecific peripheral $\beta$ adrenergic receptors, yet there is some evidence to suggest that it may also act by enhancing GABA receptivity in the central nervous system. ${ }^{99}$

\section{Bench}

The clinical observation of the importance of the GABA system in the treatment of ET is substantiated by a number of scientific studies. One study demonstrated that cerebrospinal fluid levels of GABA were significantly reduced in 20 patients with ET compared with 16 control subjects. ${ }^{101}$ A recent PET study ${ }^{102}$ reported increased ${ }^{11} \mathrm{C}$-flumazenil binding at GABA-ergic receptor sites in the ET cerebellum. Furthermore, in another recent ${ }^{11} \mathrm{C}$ flumazenil PET study, the severity of tremor in ET correlated with the abnormalities found in GABA receptor binding, suggesting a primary GABA-ergic deficiency or a functional abnormality at the level of GABA(A) receptor subtypes in ET. ${ }^{103}$ A recent postmortem study demonstrated reductions in $\operatorname{GABA}(\mathrm{A})$ and $\mathrm{GABA}(\mathrm{B})$ receptors in the dentate nucleus in ET. ${ }^{84}$ Finally, one of the features to emerge from postmortem studies is a reduction in Purkinje cell counts. ${ }^{45}$

\section{Bedside}

Taking these observations to the bedside will be a challenge. Clearly, there is already a plethora of GABA-ergic agents that have been tried, with only modest success, in the treatment of ET. The development of more effective medications will be dependent on a more detailed understanding of the specific GABA-ergic abnormalities in ET. Even in the non-disease state, GABA biology in the cerebellum is complex, with several cerebellar neurons, aside from Purkinje cells, releasing this neurotransmitter. How this complex biology is altered in ET is not fully known, but will be important in terms of developing more targeted GABA-ergic agents.

\section{Conclusions}

Recent years have witnessed a notable increase in research on ET, with consequent advances in our understanding of this entity. Observations arising from clinical practice have motivated scientific studies of this disorder. In turn, the results of scientific studies are beginning to be translated back to the bedside and may advance treatments of the future. Hence, we have seen a flow of new ideas and concepts back and forth across clinical and scientific realms. The success of future attempts to advance therapeutics will depend on this flow of ideas.

\section{Acknowledgments}

National Institutes of Health R01NS042859, R01 NS039422, R01 NS085136.

\section{References}

1. Louis ED, Ferreira JJ. How common is the most common adult movement disorder? Update on the worldwide prevalence of essential tremor. Mov Disord. 2010; 25(5):534-41. [PubMed: 20175185]

2. Elble RJ. Essential tremor is a monosymptomatic disorder. Mov Disord. 2002; 17(4):633-7. [PubMed: 12210850] 
3. Benito-León J. Essential tremor: from a monosymptomatic disorder to a more complex entity. Neuroepidemiology. 2008; 31(3):191-2. [PubMed: 18784419]

4. Brennan KC, Jurewicz EC, Ford B, Pullman SL, Louis ED. Is essential tremor predominantly a kinetic or a postural tremor? A clinical and electrophysiological study. Mov Disord. 2002; 17(2): 313-6. [PubMed: 11921117]

5. Louis ED. The primary type of tremor in essential tremor is kinetic rather than postural: crosssectional observation of tremor phenomenology in 369 cases. Eur J Neurol. 2013; 20(4):725-7. [PubMed: 22925197]

6. Thenganatt MA, Louis ED. Distinguishing essential tremor from Parkinson's disease: bedside tests and laboratory evaluations. Expert Rev Neurother. 2012; 12(6):687-96. [PubMed: 22650171]

7. Sternberg EJ, Alcalay RN, Levy OA, Louis ED. Postural and Intention Tremors: A Detailed Clinical Study of Essential Tremor vs. Parkinson's Disease. Front Neurol. 2013; 4:51. [PubMed: 23717300]

8. Deuschl G, Wenzelburger R, Löffler K, Raethjen J, Stolze H. Essential tremor and cerebellar dysfunction clinical and kinematic analysis of intention tremor. Brain. 2000; 123(Pt 8):1568-80. [PubMed: 10908187]

9. Louis ED, Frucht SJ, Rios E. Intention tremor in essential tremor: Prevalence and association with disease duration. Mov Disord. 2009; 24(4):626-7. [PubMed: 19185016]

10. Cohen O, Pullman S, Jurewicz E, Watner D, Louis ED. Rest tremor in patients with essential tremor: prevalence, clinical correlates, and electrophysiologic characteristics. Arch Neurol. 2003; 60(3):405-10. [PubMed: 12633153]

11. Hubble JP, Busenbark KL, Pahwa R, Lyons K, Koller WC. Clinical expression of essential tremor: effects of gender and age. Mov Disord. 1997; 12(6):969-72. [PubMed: 9399222]

12. Hardesty DE, Maraganore DM, Matsumoto JY, Louis ED. Increased risk of head tremor in women with essential tremor: longitudinal data from the Rochester Epidemiology Project. Mov Disord. 2004; 19(5):529-33. [PubMed: 15133816]

13. Louis ED, Rios E, Applegate LM, Hernandez NC, Andrews HF. Jaw tremor: prevalence and clinical correlates in three essential tremor case samples. Mov Disord. 2006; 21(11):1872-8. [PubMed: 16941462]

14. Louis ED, Pellegrino KM, Rios E. Unawareness of head tremor in essential tremor: a study of three samples of essential tremor patients. Mov Disord. 2008; 23(16):2423-4. [PubMed: 18831531]

15. Putzke JD, Whaley NR, Baba Y, Wszolek ZK, Uitti RJ. Essential tremor: predictors of disease progression in a clinical cohort. J Neurol Neurosurg Psychiatry. 2006; 77(11):1235-7. [PubMed: 17043291]

16. Louis ED, Agnew A, Gillman A, Gerbin M, Viner AS. Estimating annual rate of decline: prospective, longitudinal data on arm tremor severity in two groups of essential tremor cases. $\mathrm{J}$ Neurol Neurosurg Psychiatry. 2011; 82(7):761-5. [PubMed: 21436230]

17*. Louis ED. 'Essential Tremor' or 'the Essential Tremors': Is This One Disease or a Family of Diseases? Neuroepidemiology. 2013; 42(2):81-9. There is accumulating evidence that the entity referred to as 'essential tremor' (ET) is not a single disease. It may be a family of diseases better referred to as 'the ETs'. This review summarizes the evidence that ET may be a family of disease. [PubMed: 24335621]

18. Kronenbuerger M, Konczak J, Ziegler W, et al. Balance and motor speech impairment in essential tremor. Cerebellum. 2009; 8(3):389-98. [PubMed: 19452239]

19. Earhart GM, Clark BR, Tabbal SD, Perlmutter JS. Gait and balance in essential tremor: variable effects of bilateral thalamic stimulation. Mov Disord. 2009; 24(3):386-91. [PubMed: 19006189]

20. Parisi SL, Héroux ME, Culham EG, Norman KE. Functional mobility and postural control in essential tremor. Arch Phys Med Rehabil. 2006; 87(10):1357-64. [PubMed: 17023246]

21. Stolze H, Petersen G, Raethjen J, Wenzelburger R, Deuschl G. The gait disorder of advanced essential tremor. Brain. 2001; 124(Pt 11):2278-86. [PubMed: 11673328]

22. Hoskovcová M, Ulmanová O, Sprdlík O, et al. Disorders of balance and gait in essential tremor are associated with midline tremor and age. Cerebellum. 2012; 12(1):27-34. [PubMed: 22535593]

23. Louis ED, Rios E, Rao AK. Tandem gait performance in essential tremor: clinical correlates and association with midline tremors. Mov Disord. 2010; 25(11):1633-8. [PubMed: 20629168] 
24. Rao AK, Uddin J, Gillman A, Louis ED. Cognitive motor interference during dual-task gait in essential tremor. Gait Posture. 2013; 38(3):403-9. [PubMed: 23369662]

25. Singer C, Sanchez-Ramos J, Weiner WJ. Gait abnormality in essential tremor. Mov Disord. 1994; 9(2):193-6. [PubMed: 8196682]

26. Louis ED, Galecki M, Rao AK. Four Essential Tremor Cases with Moderately Impaired Gait: How Impaired can Gait be in this Disease? Tremor Other Hyperkinet Mov (N Y). 2013; 3

27*. Gitchel GT, Wetzel PA, Baron MS. Slowed saccades and increased square wave jerks in essential tremor. Tremor Other Hyperkinet Mov (N Y). 2013; 3 Sixty ET patients and 60 age-matched controls were studied using a video-based eye tracker to assess binocular eye position. Oculomotor function was assessed while subjects followed random horizontally and vertically step-displaced targets. In contrast to normally swift onset and efficient acceleration/deceleration movements, saccades in ET patients were characterized by abnormally prolonged latencies and slowed velocity profiles. This study demonstrated the presence of novel oculomotor deficits in patients with ET, which are distinct from the eye movement dysfunctions of other movement disorders. The findings support a role of cerebellar dysfunction in disease pathogenesis.

28. Helmchen C, Hagenow A, Miesner J, et al. Eye movement abnormalities in essential tremor may indicate cerebellar dysfunction. Brain. 2003; 126(Pt 6):1319-32. [PubMed: 12764054]

29. Bares M, Lungu OV, Husárová I, Gescheidt T. Predictive motor timing performance dissociates between early diseases of the cerebellum and Parkinson's disease. Cerebellum. 2010; 9(1):124-35. [PubMed: 19851820]

30. Trillenberg P, Führer J, Sprenger A, et al. Eye-hand coordination in essential tremor. Mov Disord. 2006; 21(3):373-9. [PubMed: 16211601]

31. Avanzino L, Bove M, Tacchino A, et al. Cerebellar involvement in timing accuracy of rhythmic finger movements in essential tremor. Eur J Neurosci. 2009; 30(10):1971-9. [PubMed: 19912337]

32. Janicki SC, Cosentino S, Louis ED. The cognitive side of essential tremor: what are the therapeutic implications? Ther Adv Neurol Disord. 2013; 6(6):353-68. [PubMed: 24228071]

33. Louis ED, Huey ED, Gerbin M, Viner AS. Apathy in essential tremor, dystonia, and Parkinson's disease: a comparison with normal controls. Mov Disord. 2012; 27(3):432-4. [PubMed: 22183872]

34. Louis ED, Benito-León J, Bermejo-Pareja F. Self-reported depression and anti-depressant medication use in essential tremor: cross-sectional and prospective analyses in a population-based study. Eur J Neurol. 2007; 14(10):1138-46. [PubMed: 17708753]

35. Louis ED, Ford B, Barnes LF. Clinical subtypes of essential tremor. Arch Neurol. 2000; 57(8): 1194-8. [PubMed: 10927801]

36. Louis ED. Factor analysis of motor and nonmotor signs in essential tremor: are these signs all part of the same underlying pathogenic process? Neuroepidemiology. 2009; 33(1):41-6. [PubMed: 19365141]

37. Louis ED, Gerbin M, Galecki M. Essential tremor 10, 20, 30, 40: clinical snapshots of the disease by decade of duration. Eur J Neurol. 2013; 20(6):949-54. [PubMed: 23521518]

38. Louis ED. Essential tremors: a family of neurodegenerative disorders? Arch Neurol. 2009; 66(10): 1202-8. [PubMed: 19822775]

39. Song IU, Park JW, Chung SW, Chung YA. Differences in cerebral perfusion according to phenotypes of essential tremor: brain perfusion SPECT study using SPM analysis. Neurol Sci. In Press.

40. Quattrone A, Cerasa A, Messina D, et al. Essential head tremor is associated with cerebellar vermis atrophy: a volumetric and voxel-based morphometry MR imaging study. AJNR Am J Neuroradiol. 2008; 29(9):1692-7. [PubMed: 18653686]

41. Bagepally BS, Bhatt MD, Chandran V, et al. Decrease in cerebral and cerebellar gray matter in essential tremor: a voxel-based morphometric analysis under 3T MRI. J Neuroimaging. 2012; 22(3):275-8. [PubMed: 21447032]

42. Cerasa A, Messina D, Nicoletti G, et al. Cerebellar atrophy in essential tremor using an automated segmentation method. AJNR Am J Neuroradiol. 2009; 30(6):1240-3. [PubMed: 19342539]

43. Shill HA, Adler CH, Sabbagh MN, et al. Pathologic findings in prospectively ascertained essential tremor subjects. Neurology. 2008; 70(16 Pt 2):1452-5. [PubMed: 18413570] 
44. Rajput A, Robinson CA, Rajput AH. Essential tremor course and disability: A clinicopathologic study of 20 cases. Neurology. 2004; 62(6):932-6. [PubMed: 15037695]

45. Louis ED, Faust PL, Vonsattel JP, et al. Neuropathological changes in essential tremor: 33 cases compared with 21 controls. Brain. 2007; 130(Pt 12):3297-307. [PubMed: 18025031]

46. Louis ED, Honig LS, Vonsattel JP, Maraganore DM, Borden S, Moskowitz CB. Essential tremor associated with focal nonnigral Lewy bodies: a clinicopathologic study. Arch Neurol. 2005; 62(6): 1004-7. [PubMed: 15956174]

47. Louis ED, Mazzoni P, Ma KJ, et al. Essential tremor with ubiquitinated intranuclear inclusions and cerebellar degeneration. Clin Neuropathol. 2012; 31(3):119-26. [PubMed: 22551915]

48. Louis ED, Babij R, Ma K, Cortés E, Vonsattel JP. Essential tremor followed by progressive supranuclear palsy: postmortem reports of 11 patients. J Neuropathol Exp Neurol. 2013; 72(1):817. [PubMed: 23242279]

49. Aridon P, Ragonese P, De Fusco M, Salemi G, Casari G, Savettieri G. Further evidence of genetic heterogeneity in familial essential tremor. Parkinsonism Relat Disord. 2008; 14(1):15-8. [PubMed: 17703985]

50. Macerollo A, Bhatia KP. FUS gene mutations cause essential tremor: a surprise but also confirms genetic heterogeneity of essential tremor. Mov Disord. 2013; 28(3):290. [PubMed: 23526429]

51. Kuhlenbaumer G, Hopfner F, Deuschl G. Genetics of essential tremor: Meta-analysis and review. Neurology. 2014; 82(11):1000-7. [PubMed: 24532269]

52. Louis ED. Treatment of Essential Tremor: Are there Issues We are Overlooking? Front Neurol. 2012; 2:91. [PubMed: 22275907]

53. Obwegeser AA, Uitti RJ, Turk MF, Strongosky AJ, Wharen RE. Thalamic stimulation for the treatment of midline tremors in essential tremor patients. Neurology. 2000; 54(12):2342-4. [PubMed: 10881269]

54. Song IU, Kim JS, Lee SB, et al. Effects of zonisamide on isolated head tremor. Eur J Neurol. 2008; 15(11):1212-5. [PubMed: 18754763]

55. Chung SJ, Kwon H, Lee DK, et al. Neuroanatomical heterogeneity of essential tremor according to propranolol response. PLoS One. 2013; 8(23):e84054. [PubMed: 24358327]

56. Klebe S, Stolze H, Grensing K, Volkmann J, Wenzelburger R, Deuschl G. Influence of alcohol on gait in patients with essential tremor. Neurology. 2005; 65(1):96-101. [PubMed: 16009892]

57. Louis ED, Rios E, Rao AK. Tandem gait performance in essential tremor: clinical correlates and association with midline tremors. Mov Disord. 2010; 25(11):1633-8. [PubMed: 20629168]

58. Rao AK, Gillman A, Louis ED. Quantitative gait analysis in essential tremor reveals impairments that are maintained into advanced age. Gait Posture. 2011; 34(1):65-70. [PubMed: 21478017]

59. Louis, ED. Essential tremor and other forms of kinetic tremor. In: Grimaldi, G.; Manto, M., editors. Mechanisms and Emerging Therapies in Tremor Disorders. New York: Springer; 2013. p. 167-201.

60. Köster B, Deuschl G, Lauk M, Timmer J, Guschlbauer B, Lücking CH. Essential tremor and cerebellar dysfunction: abnormal ballistic movements. J Neurol Neurosurg Psychiatry. 2002; 73(4):400-5. [PubMed: 12235308]

61. Leegwater-Kim J, Louis ED, Pullman SL, et al. Intention tremor of the head in patients with essential tremor. Mov Disord. 2006; 21(11):2001-5. [PubMed: 16960854]

62. Farkas Z, Szirmai I, Kamondi A. Impaired rhythm generation in essential tremor. Mov Disord. 2006; 21(8):1196-9. [PubMed: 16700029]

63. Dupuis MJ, Delwaide PJ, Boucquey D, Gonsette RE. Homolateral disappearance of essential tremor after cerebellar stroke. Mov Disord. 1989; 4(2):183-7. [PubMed: 2733709]

64. Rajput AH, Maxood K, Rajput A. Classic essential tremor changes following cerebellar hemorrhage. Neurology. 2008; 71(21):1739-40. [PubMed: 19015491]

65. Baizabal-Carvallo JF, Kagnoff MN, Jimenez-Shahed J, Fekete R, Jankovic J. The safety and efficacy thalamic deep brain stimulation in essential tremor: 10 years and beyond. J Neurol Neurosurg Psychiatry. 2014; 85(5):567-72. [PubMed: 24096713] 
66. Benabid AL, Pollak P, Seigneuret E, Hoffmann D, Gay E, Perret J. Chronic VIM thalamic stimulation in Parkinson's disease, essential tremor and extra-pyramidal dyskinesias. Acta Neurochir Suppl (Wien). 1993; 58:39-44. [PubMed: 8109299]

67*. Passamonti L, Cerasa A, Quattrone A. Neuroimaging of Essential Tremor: What is the Evidence for Cerebellar Involvement? Tremor Other Hyperkinet Mov (N Y). 2012; 2 The authors discussed the neuroimaging research investigating the brain structure and function of ET patients relative to healthy controls. They concluded that current neuroimaging research provides converging evidence for the role of the cerebellum in the pathophysiology of ET, although some inconsistencies exist, particularly in structural studies. These inconsistencies may depend on the high clinical heterogeneity of ET as well as on differences among the experimental methods used across studies.

68. Bucher SF, Seelos KC, Dodel RC, Reiser M, Oertel WH. Activation mapping in essential tremor with functional magnetic resonance imaging. Ann Neurol. 1997; 41(1):32-40. [PubMed: 9005863]

69. Jenkins IH, Bain PG, Colebatch JG, et al. A positron emission tomography study of essential tremor: evidence for overactivity of cerebellar connections. Ann Neurol. 1993; 34(1):82-90. [PubMed: 8517685]

70. Wills AJ, Jenkins IH, Thompson PD, Findley LJ, Brooks DJ. Red nuclear and cerebellar but no olivary activation associated with essential tremor: a positron emission tomographic study. Ann Neurol. 1994; 36(4):636-42. [PubMed: 7944296]

71. Colebatch JG, Findley LJ, Frackowiak RS, Marsden CD, Brooks DJ. Preliminary report: activation of the cerebellum in essential tremor. Lancet. 1990; 336(8722):1028-30. [PubMed: 1977019]

72. Louis ED, Shungu DC, Chan S, Mao X, Jurewicz EC, Watner D. Metabolic abnormality in the cerebellum in patients with essential tremor: a proton magnetic resonance spectroscopic imaging study. Neurosci Lett. 2002; 333(1):17-20. [PubMed: 12401550]

73. Pagan FL, Butman JA, Dambrosia JM, Hallett M. Evaluation of essential tremor with multi-voxel magnetic resonance spectroscopy. Neurology. 2003; 60(8):1344-7. [PubMed: 12707440]

74. Shin DH, Han BS, Kim HS, Lee PH. Diffusion tensor imaging in patients with essential tremor. AJNR Am J Neuroradiol. 2008; 29(1):151-3. [PubMed: 17921227]

75. Klein JC, Lorenz B, Kang JS, et al. Diffusion tensor imaging of white matter involvement in essential tremor. Hum Brain Mapp. 2011; 32(6):896-904. [PubMed: 20572209]

76. Nicoletti G, Manners D, Novellino F, et al. Diffusion tensor MRI changes in cerebellar structures of patients with familial essential tremor. Neurology. 2010; 74(12):988-94. [PubMed: 20308683]

77. Benito-León J, Alvarez-Linera J, Hernández-Tamames JA, Alonso-Navarro H, Jiménez-Jiménez FJ, Louis ED. Brain structural changes in essential tremor: voxel-based morphometry at 3-Tesla. J Neurol Sci. 2009; 287(1-2):138-42. [PubMed: 19717167]

78. Cerasa A, Messina D, Nicoletti G, et al. Cerebellar atrophy in essential tremor using an automated segmentation method. AJNR Am J Neuroradiol. 2009; 30(6):1240-3. [PubMed: 19342539]

79. Yu M, Ma K, Faust PL, et al. Increased number of Purkinje cell dendritic swellings in essential tremor. Eur J Neurol. 2012; 19(4):625-30. [PubMed: 22136494]

80. Axelrad JE, Louis ED, Honig LS, et al. Reduced Purkinje cell number in essential tremor: a postmortem study. Arch Neurol. 2008; 65(1):101-7. [PubMed: 18195146]

81. Kuo SH, Erickson-Davis C, Gillman A, Faust PL, Vonsattel JP, Louis ED. Increased number of heterotopic Purkinje cells in essential tremor. J Neurol Neurosurg Psychiatry. 2011; 82(9):1038_ 40. [PubMed: 20802031]

82. Erickson-Davis CR, Faust PL, Vonsattel JP, Gupta S, Honig LS, Louis ED. "Hairy baskets" associated with degenerative Purkinje cell changes in essential tremor. J Neuropathol Exp Neurol. 2010; 69(3):262-71. [PubMed: 20142764]

83. Kuo SH, Tang G, Louis ED, et al. Lingo-1 expression is increased in essential tremor cerebellum and is present in the basket cell pinceau. Acta Neuropathol. 2013; 125(6):879-89. [PubMed: 23543187]

84. Paris-Robidas S, Brochu E, Sintes M, et al. Defective dentate nucleus GABA receptors in essential tremor. Brain. 2012; 135(Pt 1):105-16. [PubMed: 22120148]

85. Speelman JD, Schuurman PR, de Bie RM, Bosch DA. Thalamic surgery and tremor. Mov Disord. 1998; 13(Suppl 3):103-6. [PubMed: 9827604] 
86. Kondziolka D, Ong JG, Lee JY, Moore RY, Flickinger JC, Lunsford LD. Gamma Knife thalamotomy for essential tremor. J Neurosurg. 2008; 108(1):111-7. [PubMed: 18173319]

87. Elias WJ, Huss D, Voss T, et al. A pilot study of focused ultrasound thalamotomy for essential tremor. N Engl J Med. 2013; 369(7):640-8. [PubMed: 23944301]

88. Larsson T, Sjogren T. Essential tremor: a clinical and genetic population study. Acta Psychiatr Scand Suppl. 1960; 36(144):1-176. [PubMed: 14414307]

89. Critchley M. Observations of essential (heredofamilial) tremor. Brain. 1949; 72(Pt 2):113-39. [PubMed: 18136705]

90. Louis ED. Re-thinking the biology of essential tremor: from models to morphology. Parkinsonism Related Disord. 2014; 20(Suppl 1):S88-93.

91. Benito-León J, Bermejo-Pareja F, Louis ED. Incidence of essential tremor in three elderly populations of central Spain. Neurology. 2005; 64(10):1721-5. [PubMed: 15911798]

92. Louis ED, Thawani SP, Andrews HF. Prevalence of essential tremor in amultiethnic, communitybased study in northern Manhattan, New York, N.Y. Neuroepidemiology. 2009; 32(3):208-14. [PubMed: 19169043]

93. Benito-León J, Bermejo-Pareja F, Morales-González JM, et al. Incidence of Parkinson disease and parkinsonism in three elderly populations of central Spain. Neurology. 2004; 6(5):734-41. [PubMed: 15007123]

94. Thawani SP, Schupf N, Louis ED. Essential tremor is associated with dementia: prospective population-based study in New York. Neurology. 2009; 73(8):621-5. [PubMed: 19704081]

95. Bermejo-Pareja F, Louis ED, Benito-León J. Risk of incident dementia in essential tremor: a population-based study. Mov Disord. 2007; 22(11):1573-80. [PubMed: 17516478]

96. Louis ED, Faust PL, Vonsattel JP. Purkinje cell loss is a characteristic of essential tremor: towards a more mature understanding of pathogenesis. Parkinsonism Relat Disord. 2012; 18(8):1003-4. [PubMed: 22795481]

97. Louis ED. From Neurons to Neuron Neighborhoods: the Rewiring of the Cerebellar Cortex in Essential Tremor. Cerebellum. In Press.

98**. Bonuccelli U. Essential tremor is a neurodegenerative disease. J Neural Transm. 2012; 119(11): 1383-7. There are many lines of evidence supporting the idea that ET is more than a monosymptomatic disorder and that all the clinical manifestations of this disorder are sustained by a neurodegenerative process. The most important lines of evidence in favor of a neurodegenerative nature of ET are: the anatomic and neuroimaging data demonstrating a pathologic process involving the cerebellum and/or brainstem; the progression of symptom severity with disease duration; and the lack of spontaneous remission of this condition. All of this evidence is supported by recent studies that are summarized in this review. [PubMed: 23011236]

99. Louis ED. A new twist for stopping the shakes? Revisiting GABAergic therapy for essential tremor. Arch Neurol. 1999; 56(7):807-8. [PubMed: 10404981]

100. Rincon F, Louis ED. Benefits and risks of pharmacological and surgical treatments for essential tremor: disease mechanisms and current management. Expert Opin Drug Saf. 2005; 4(5):899_ 913. [PubMed: 16111452]

101. Málly J, Baranyi M, Vizi ES. Change in the concentrations of amino acids in CSF and serum of patients with essential tremor. J Neural Transm. 1996; 103(5):555-60. [PubMed: 8811501]

102. Boecker H, Weindl A, Brooks DJ, et al. GABAergic dysfunction in essential tremor: an 11Cflumazenil PET study. J Nucl Med. 2010; 51(7):1030-5. [PubMed: 20554735]

103. Gironell A, Figueiras FP, Pagonabarraga J, et al. Gaba and serotonin molecular neuroimaging in essential tremor: a clinical correlation study. Parkinsonism Relat Disord. 2012; 18(7):876-80. [PubMed: 22595620] 


\section{Bullet Points}

- Observations on ET arising from clinical practice/clinical studies have guided scientific studies of this disorder, and the results of scientific studies are beginning to be translated back to the bedside.

- Recent ET research has given rise to several novel and intriguing ideas about the disease. These include the ideas that ET may represent a family of diseases rather than a single disease, that ET seems to be a disease of the cerebellum or cerebellar system, that ET may be neurodegenerative, and that low gamma aminobutyric acid tone seems to be a central feature of ET.

- As with many emerging ideas, there is significant discussion and debate over these emerging ideas.

- The flow of ideas, from clinical observations about ET, to their translation into scientific studies, and their translation back to the bedside is eventually expected to lead to improvements at the patient interface. 